\title{
Assessment of nutritional and metabolic profiles of pea shoots: The new ready-to-eat baby-leaf vegetable
}

\author{
J. Santos, M. Herrero, J.A.Mendiola, M.T. Oliva-Teles, E. Ibáñez, C. Delerue-Matos, M.B.P.P. Oliveira
}

\section{ABSTRACT}

Pea-shoots are a new option as ready-to-eat baby-leaf vegetable. However, data about the nutritional composi-tion and the shelf-life stability of these leaves, especially their phytonutrient composition is scarce. In this work, the macronutrient, micronutrient and phytonutrients profile of minimally processed pea shoots were evaluated the beginning and at the end of a 10-day storage period. Several physicochemical characteristics (color, $\mathrm{pH}$, total soluble solids, and total titratable acidity) were also monitored. Standard AOAC methods were applied in the nutritional value evaluation, while chromatographic methods with UV-vis and mass detection were used to analyze free forms of vitamins (HPLC-DAD-ESI-MS/MS), carotenoids (HPLC-DAD-APCI-MS ${ }^{\mathrm{n}}$ ) and flavonoid compounds (HPLCDAD-ESI-MS ${ }^{n}$ ). Atomic absorption spectrometry (HR-CS-AAS) was employed to characterize the mineral content of the leaves. As expected, pea leaves had a high water (91.5\%) and low fat $(0.3 \%)$ and carbohydrate (1.9\%) contents, being a good source of dietary fiber (2.1\%). Pea shoots showed a high content of vitamins $C, E$ and $A$, potassium and phosphorous compared to other ready-to-eat green leafy vegetables. The carotenoid profile revealed a high content of $\beta$ carotene and lutein, typical from green leafy vegetables. Theleaves had a mean flavonoid content of $329 \mathrm{mg} / 100 \mathrm{~g}$ of fresh product, mainly composed by glycosylated quercetin and kaempferol derivatives. Pea shoots kept their fresh appearance during the storage being colormaintained throughout the shelf-life. The nutritional composition was in general stable during storage, showing some significant ( $\mathrm{p} \mathrm{b} 0.05$ ) variation in certain water-soluble vitamins.

Keywords:

Pea shoots, Nutritional composition, Carotenoid profile, Flavonoid profile, Storage

\section{Introduction}

The consumption of green leafy vegetables is recommended due to their high content of vitamins, minerals and antioxidant phytochemi- cals, as well as low content of fat and carbohydrates (Rico, Martín- Diana, Barat, \& BarryRyan, 2007). Minimally processed vegetables sold as ready-to-eat salads are a convenient way to include vegetables in the diet. To increase variety and attract even more consumers, the fresh-cut producers seek for new varieties of leafy vegetables to add to ready-to-eat salad mixtures (Martínez-Sánchez et al., 2012). Pea shoots were recently presented as a ready-to-eat vegetable, and are recognized as a popular specialty vegetable in some parts of Asia and Africa that is gaining popularity in the United States and Europe (Miles \& Sonde, 2003).

Peas (Pisum sativum) are among the most consumed vegetables worldwide, with a registered global production of 15 million tons in 2010 (FAO, 2013). It is normally consumed as a seed food, and is a good source of proteins, vitamins and minerals (Martins, 2010). The consumption of leaves of the pea plants, also known as pea shoots, is not as common as eating the peas. They are harvested in a very early maturation stage, when the leaves and tendrils are tender, crispy and have an intense pea flavor (Miles \& Sonde, 2003). This baby-leaf green leafy vegetable can be eaten raw in salads, or cooked with others ingre- dients ("Pea shoots, 2013"). Accordingly to Miles and Sonde (2003), pea shoots are a very perishable product with a high market value, when compared to other common leafy vegetables. As a minimally processed vegetable, pea leaves can be packed solely or in ready-to-eat salad mix- tures and their quality and safety is strictly dependent on the mainte- nance of refrigerating conditions during storage (Rico et al., 2007).

The pea plant is one of the most-studied vegetables, being a wellestablished classic model for genetics and agronomic studies(Edelenbos, Christensen, \& Grevsen, 2001; Hamada \& El-Enany, 1994; Wong, Bhalla, Ottenhof, \& Singh, 2008). Its origins are in Middle East and Mediterranean regions, integrating the diet of early civilizations (Smýkal, Coyne, Redden, \& Maxted, 2013). The nutritional composition of peas is published in official nutritional tables (Martins, 2010). On the otherhand, the nutritional quality of pea shoots is notmentioned. There are however some nutritional allegations of being rich in vitamin C and A in the producers' website ("Pea shoots, 2013"). Specific scientific data regarding the nutritional composition of pea shoots is scarce, being most of the available information based in the generalization of the 
green leafy vegetables composition (Miles \& Sonde, 2003). In this context, the objective of this work was to characterize and compare physicochemical characteristics as well as nutritional quality and phytonutrients composition of minimally processed pea shoots stored under refrigerated conditions. Color, total soluble solids (TSS), total titratable acidity (TTA), pH, macronutrient composition and also minerals, vitamins, carotenoids and flavonoids contents of pea shoots were assessed.

\section{Material andMethods}

\subsection{Samples}

Minimally processed pea shoots (Pisum sativum) were obtained from a producer (Odemira, Portugal). Upon arrival to the laboratory, one day after processed (washed, cut and packed), pea shoots weredivided in two groups. One was prepared for analysis and the second was stored under refrigerated conditions $\left(3 \pm 1^{\circ} \mathrm{C}\right)$ for 10 days. About $200 \mathrm{~g}$ of fresh leaves from each group were used for color, TSS, TTA, pH and macronutrient analyses. The fresh leaves were grinded in a knife mill and used for protein, fat, ash and dietary fiber determi- nations. Vitamins, minerals, carotenoids and flavonoids were deter- mined in freeze-dried pea shoots samples (Telstar Cryodos-80, Terrassa, Barcelona), that were powdered in a knife mill (GM 200, RETSCH, Haan, Germany) and stored protected from light, oxygen and heat until analysis.

\subsection{Quality analysis}

\subsubsection{Physicochemical characteristics}

Leaves color parameters $L^{*}, a^{*}$ and $b^{*}$ were determined with a tri- stimulus colorimeter (CR-400Chroma Meter, Konica Minolta, Japan), where L* defines the lightness $\left(0 \mathrm{~b} \mathrm{~L}^{*} \mathrm{~b} 100\right)$ variation. Parameters $\mathrm{a} *$

define the red $(+)$ to green $(-)$ and $b^{*}$ the blue $(-)$ to yellow $(+)$ chromaticity. Thesewereused tocalculatethehueangle $(\mathrm{h}=\mathrm{o}=\operatorname{arctang}$

$\left.\left(b^{*} / a^{*}\right)\right)$ and chroma $\left(C^{*}=\left(a^{* 2}+b^{* 2}\right)^{1 / 2}\right)$ values. The equipment was set up for illuminant D65 with 10o observer angle and calibrated using a standard white plate. Forty measurements were made in different leaves at each sampling day. Total soluble solids (TSS) were determined on pea shoots juice, obtained by grinding $10 \mathrm{~g}$ of fresh leaves in a knife mill, in a Digital Refractometer (oBrix, HI 9680, Hanna Instruments, EUA). The pH was measured with a pH-meter (Crison Instruments, Barcelona, Spain) in $10 \mathrm{~g}$ of leaves homogenized in $20 \mathrm{~mL}$ of deionised water (AOAC, 2000). Total titratable acidity (TTA) was determined accordingly to the Official method 942.15 (AOAC, 2000). Briefly, 10 grams of fresh leaves were homogenized in $100 \mathrm{ml}$ of deionized water and then titrated with $0.1 \mathrm{M} \mathrm{NaOH}$ to $\mathrm{pH} 8.1$ and expressed as the units of citric acid ( $\mathrm{mg} / 100 \mathrm{~g}$ ) on a fresh weight (f.w.) basis.

\subsubsection{Nutritional Composition}

The water, protein (factor of 6.25), fat, ashes and total dietary fiber contents were determined accordingly to the AOAC (2000) methods, in the samples after one and ten days of storage. Protein content was es- timated by the Kjeldahl method, fat by Soxhlet extracting method, whereas ash content was determined by incineration at $600 \pm 15{ }^{\circ} \mathrm{C}$ and dietary fiber by an enzymatic gravimetric method. All values were presented as a percentage, being carbohydrates calculated by differ- ence. All proximate composition analyses were done, at least, in tripli- cate. Energy was calculated according AtwaterFactors(Otten, Hellwig,

\& Meyers, 2006).

Mineral composition was evaluated by a High Resolution-Continuum Source Atomic Absorption Spectrophotometric (HR-CS-AAS) method optimized by Santos, Oliva-Teles, Delerue-Matos, and Oliveira (2014). Briefly, $150 \mathrm{mg}$ of freeze dried pea shoots were digested with $9 \mathrm{ml}$ of nitric acid diluted with ultrapure water (43.3\%) by microwave assisted digestion (MARS-X, CEM, Mathews, NC, USA). Potassium, sodium, calci- um, magnesium, iron, manganese and zinc were analyzed with flame

extracted with 70\% $\mathrm{MeOH}$ in a pressurized liquid extraction system (ASE 200, Dionex, Sunnyvale, CA, USA) with $11 \mathrm{~mL}$ extraction cells and following a procedure previously described (Miron, Plaza, Bahrim, Ibáñez, \& Herrero, 2011). The extraction conditions were the following: extraction time, $20 \mathrm{~min}$; atomization (FAAS) (ContrAA 700, Analytik Jena, Germany), while cop- per was determined by electrothermal (EAAS) atomization. Phospho- rous content was measured according to the 4500-P standard method (Greenberg, Clesceri, \& Eaton, 1992) the vanadomolybdophosphoric acid colorimetric method in a UV-vis spectrophotometer (Evolution ${ }^{\mathrm{TM}}$ 300, Thermo Scientific, Waltham, MA, USA). Four replicates of pea shoots from each sampling day were used in minerals determination.

Several free forms of water-soluble vitamins ( $C_{1} B_{1}, B_{2}, B_{3}, B_{5}, B_{6}$ and $\left.B_{9}\right)$ and fat-soluble vitamins (Pro-vitamin A and $E$ ( $\alpha$-tocopherol)) wereassessed by HPLCMS/MS and HPLC-DAD methods described by Santos, Mendiola, Oliveira, Ibáñez, and Herrero (2012). Briefly, $250 \mathrm{mg}$ of freeze dried sample was extracted with 16 $\mathrm{mL}$ of $10 \mathrm{mM}$ ammonium acetate/ methanol $1: 1(\mathrm{v} / \mathrm{v})$ in an ultrasound bath for 15 minutes. After centrifu- gation (14000 g; $15 \mathrm{~min}$ ) the supernatant was concentrated under nitrogen stream and injected into a HPLC-ESI-MS/MS system (Thermo Scientific, San Jose, CA, USA) to determine the water-soluble vitamin content. The solid residue was re-extracted twice with ethyl acetate $(0.1 \% \mathrm{BHT})(6+6 \mathrm{~mL})$ in an ultrasound bath $(15 \mathrm{~min})$. After centri- fuged $(14000 \mathrm{~g}, 15 \mathrm{~min})$, the two supernatants were combined and dried under nitrogen stream. The residue was re-dissolved in $3 \mathrm{~mL}$ of ethyl acetate and injected in a HPLC-DAD system (Agilent 1100 Santa Clara, CA, USA) to determine fat-soluble vitamin content of the samples. Pea shoot vitamin contents were determined along the storage period (day 1 and day 10). The results were expressed as $\mathrm{mg} / 100 \mathrm{~g}$, with exception for vitamin $\mathrm{A}$, expressed as $\mathrm{mg}$ Retinol Activity Equivalent (RAE) calculated accordingly to the following equation: $1 \mathrm{mg} \mathrm{RAE}=12 \mathrm{mg} \beta$-carotene (Otten et al., 2006).

\subsubsection{Carotenoid profile}

The extraction procedure used to study the carotenoid profile was described previously for the analysis of fat-soluble vitamins (Santos et al., 2012). Once re-dissolved, the extract was filtered through a

$0.45 \mu \mathrm{m}$ nylon filter and injected in a HPLC-DAD-APCI-MS ${ }^{\mathrm{n}}$ system.

The equipment used was an Agilent 1200 liquid chromatograph (Agilent, SantaClara, CA, USA)equipped withanautosampler, aDAD, and directly coupled to an ion trap mass spectrometer (Agilent ion trap 6320) via an atmospheric pressure chemical ionization (APCI) interface, using an YMC C30 analytical column ( $5 \mu \mathrm{m}$ particle size, 250

$\times 4.6 \mathrm{~mm}$ i.d.) (YMC, Schermbeck, Germany). The mobile phases (A: methanol/water, 90:10 v/v; B: Methyl tert-butyl ether/methanol/ water, $90: 6: 4, \mathrm{v} / \mathrm{v} / \mathrm{v}$ ) eluted in the following gradient: $0 \mathrm{~min}, 6.5 \% \mathrm{~B} ; 8 \mathrm{~min}, 6.5 \% \mathrm{~B} ; 43$ $\mathrm{min}, 100 \% \mathrm{~B} ; 46 \mathrm{~min}, 6.5 \% \mathrm{~B} ; 55 \mathrm{~min}, 6.5 \% \mathrm{~B}$. The flow rate was $1 \mathrm{~mL} \mathrm{~min}^{-1}$ and the injection volume $10 \mu \mathrm{L}$. The DAD recorded the spectra from 220 to $700 \mathrm{~nm}$, and the chromatograms were moni- tored at $450 \mathrm{~nm}$. MS analysis was conducted with $\mathrm{APCl}$ in positive ionization mode using the following parameters: capillary voltage,

$-3.5 \mathrm{kV}$; drying temperature, $350^{\circ} \mathrm{C}$; vaporizer temperature, $400^{\circ} \mathrm{C}$; drying gas flow rate, $5 \mathrm{~L} / \mathrm{min}$; corona current (which sets the discharge

amperage for the $\mathrm{APCl}$ source), $4000 \mathrm{nA}$; nebulizer gas pressure, $60 \mathrm{psi}$. A range from $\mathrm{m} / \mathrm{z} 150$ to $\mathrm{m} / \mathrm{z} 1300$ was acquired and MS/MS automatic mode was used on the more abundant ions in the MS spectra to identify the principal fragmentation ions. The major carotenoids were identified by combining absorption spectroscopic data, chromatographic proper- ties and MS information with the values obtained from available stan- dards and data reported in the literature. To quantify the carotenoids, six different concentrations were used to construct a calibration curve of lutein (linear range $10-200 \mu \mathrm{g} \mathrm{m}^{-1}, \mathrm{R}^{2} \mathrm{~N} 0.998$ ) and $\beta$-carotene (6.25-250 $\mu \mathrm{g} \mathrm{mL}^{-1}, \mathrm{R}^{2} \mathrm{~N}$ 0.999). All xanthophylls were quantified as lutein equivalents, while the carotene isomers were quantified as $\beta$-carotene equivalents. The results were expressed in $\mathrm{mg} / 100 \mathrm{~g}$ of fresh weight (f.w.), as mean \pm standard deviation of two extracts from each sampling day.

\subsubsection{Flavonoid compounds characterization}

The flavonoids present in pea shoots were analyzed by an HPLC- DAD-ESI$M S^{n}$ method. Briefly, $500 \mathrm{mg}$ of freeze dried pea shoots were

temperature, $70{ }^{\circ} \mathrm{C}$; pressure $10 \mathrm{MPa}$; flush volume, $60 \%$. The extracts were first dried in a Rotavapor R-210 (Büchi, Labortechnik AG, Flawil, Switzerland) and later freeze-dried (Labconco Corporation, Missouri, USA). The dried extracts were re- 
dissolved in $70 \%$ methanol $\left(5 \mathrm{mg} \mathrm{mL}^{-1}\right.$ ) and filtered through a $0.45 \mu \mathrm{m}$ disposable syringe filter. For the study of acyl flavonoid deriva- tives, an alkaline hydrolysis was carried out to eliminate acid moieties ( $p$-coumaroyl, caffeoyl, feruloyl and sinapoyl), following the proceduredescribed by Francisco et al. (2009).

The analyses of both extracts (native and hydrolyzed) were carried out on an Agilent 1200 liquid chromatograph (Agilent, Santa Clara, CA, USA) equipped with an autosampler, a DAD, and directly coupled to an ion trap mass spectrometer (Agilent ion trap 6320) via an electrospray interface. The column was a Zorbax Eclipse XBD C18 (5 $\mu \mathrm{m}, 150 \times 4.6 \mathrm{~mm}$ ) (Agilent, Santa Clara, CA) and the mobile phases (A: $0.1 \%$ formic acid; B: methanol with $0.1 \%$ formic acid), elut- ed with the following gradient: $0 \mathrm{~min}, 95 \% \mathrm{~A} ; 4$ $\min , 95 \% \mathrm{~A} ; 20 \mathrm{~min}$,

$73 \%$ A; $50 \mathrm{~min}, 5 \%$ A; $57 \mathrm{~min}, 99 \%$ A; $58 \mathrm{~min}, 99 \%$ A; $60 \mathrm{~min}, 95 \% \mathrm{~A}$.

A flow rate used was of $0.7 \mathrm{~mL} \mathrm{~min}^{-1}$ and the injection volume of $10 \mu \mathrm{L}$. The UV-vis spectra were recorded from 200 to $550 \mathrm{~nm}$ and the chromatograms were monitored at $330 \mathrm{~nm}$. The MS detector operated under ESI negative ionization mode, with dry temperature of $350{ }^{\circ} \mathrm{C}$; dry gas flow of $12 \mathrm{~L} \mathrm{~min}^{-1}$; nebulizer gas pressure of $40 \mathrm{psi}$ and $3500 \mathrm{~V}$ of capillary voltage. A mass scan range was set from m/z 100 to 1000 and MS/MS automatic mode was also used. The flavo- noids were characterized according to their retention time, UV-vis and mass spectra compared to information available in the literature and available commercial standards. To quantify the flavonoid con- tents, a calibration curve was obtained from seven different concen- trations of quercetin-3-O-glucoside (linear range: 1.0-66.7 $\mu \mathrm{g} \mathrm{mL} \mathrm{mL}^{-1}, \mathrm{R}^{2} \quad \mathrm{~N}$ 0.999) and kaempferol-3-O-glucoside (linear range: $0.2-$

$14.8 \mu \mathrm{g} \mathrm{mL}{ }^{-1}, \mathrm{R}^{2} \mathrm{~N}$ 0.999). All quercetin derivatives were quantified though the quercetin-3-O-glucoside calibration curve, while kaempferol- 3-Oglucoside calibration curve was used in the case of kaempferolderivatives. The results were grouped as quercetin and kampferol derivatives, and the values presented represent the sum of the individ- ual quercetin and kaempferol derivatives compounds, respectively, found in the extracts. The results were expressed in $\mathrm{mg} / 100 \mathrm{~g}$ of fresh weight (f.w.), as mean \pm standard deviation of two extracts.

\subsection{Statisticalanalysis}

Data were expressed as mean \pm standard deviation and the differ- ences between the two days of sampling (day 1 and day 10) were tested by the oneway ANOVA. Normal distribution of data in the different samples was assessed by Kolmogorov-Smnirnov test. Statistical signifi- cance was defined for a p b 0.05 (95\% confidence level). The statistical analyses were carried out using the Statistica 8.0 software (Statsoft Inc., Tulsa, USA).

\section{Results anddiscussion}

Convenience is the key factor that leads consumers to choose mini- mally processed vegetables, increasing the intake of fresh products in their diets (Barrett, Beaulieu, \&Shewfelt, 2010). Although it could not

\section{be directly appreciated by the consumer, the nutritional quality of}

these products is also becoming a choosing factor, due to an increased perception of the possibility of preserving health by choosing a balanced diet (Poiroux-Gonord et al., 2010). Due to the lack of specific informa- tion about the nutritional composition of pea shoots, this work focused on achieving a comprehensive characterization of nutritional quality of these leaves. Micronutrient composition (vitamins and minerals) of pea leaves was evaluated, knowing that it is determined by genetic factors, but it also reflects the agronomic practices and environmental condi- tions during theirgrowth and storage(Hanson, Yang, Chang, Ledesma,

\& Ledesma, 2011; Santos et al., 2012). Carotenoids and flavonoids are phytonutrients with recognized beneficial antioxidant properties (PoirouxGonord et al., 2010). Their content is also affected by intrinsic and external factors. The levels of each nutrient were compared during the storage period to evaluate the stability of the bioactive compounds.

\subsection{Evolution of physicochemical characteristics}

The evolution of physicochemical characteristics analyzed in pea shoot is presented in Table 1. These parameters monitored the evolution of quality characteristics with major influence on the consumer's choice: color/appearance and flavor (Barrett et al., 2010). The color of minimally processed vegetables can suffer changes during storage, being the loss of greenness and the appearance of a yellowish tonality signs of the onset of senescence reactions (Barrett et al., 2010; Kidmose, Edelenbos, \& R.N., 2002). Pea shoots leaves showed a dark green color (Hue angle of $122^{\circ}$ ) that was constant during the storage period. No significant differences ( $p$ b 0.05) were found between $a^{*}$ values from the beginning and end of storage, which corroborates the preservation of the green tonality. Relatively to the other color parameters, the changes were less than $6 \%$ of the initial value recorded, being the fresh appearance maintained throughout the refrigerated storage. Normally, an evolution of $L^{*}$ values lower than 3 units is not detectable by consumers (Tomás-Callejas, Boluda, Robles, Artés, \& ArtésHernández, 2011). A slight increase of lightness $\left(L^{*}\right)$ values (between 7 and $9 \%)$ was also described during storage of red chard baby leaves (TomásCallejas et al., 2011), whereas a decrease of $L^{*}$ values was registered in watercress baby leaves (Hinojosa et al., 2013). The levels of TSS revealed a slight decrease (-18\%) during

storage, being followed by a $20 \%$ increase of the TTA(Table 1 ). A similar

evolution was found in the TSS of swiss chard leaves during storage (Roura, Davidovich, \& del Valle, 2000). The high respiration rate, normally associated to initial stages of maturation, can lead to the consumption of the sugars included in the TSS fraction, leading to a de- crease of these values during storage. These changes are directly related to metabolic processes, corresponding to the evolution of the leaf me- tabolism during storage (Roura et al., 2000), and could also represent a change in the sensorial properties of the product (especially, sweet- ness and sourness sensation) (Barrett et al., 2010). However, in pea shoots the small TSS and TTA variation, together with the even less pro- nounced variation of the $\mathrm{pH}(-4 \%)$, points to an overall preservation of flavor characteristics, when leaves are stored under low temperatures $\left(3 \pm 1{ }^{\circ} \mathrm{C}\right)$. These results highlight the possibility of preserving the pea shoots quality for at least 10 days after harvested, when properly processed and stored.

Table 1

Variation of physicochemical parameters through the storage period (mean value \pm standard deviation; $§$ means no significant variation between sampling days ( $\mathrm{p}$ b 0.05); TSS: total soluble solids; TTA: total titratable acidity)

Peashoots

Day 1

Day 10

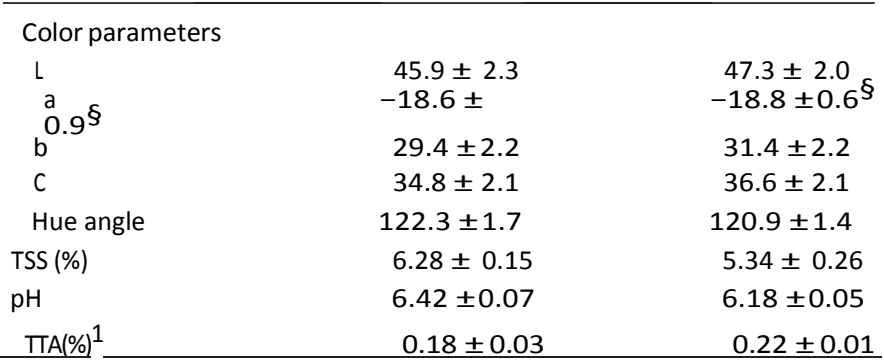


$1 \%$ of citric acid. 
Table 2

Nutritional composition of pea shoots during storage (mean value \pm standard deviation relative to fresh weight (f.w.); * means a significant variation ( $\mathrm{p}$ b 0.05) between sampling days).

\begin{tabular}{|c|c|c|}
\hline \multicolumn{3}{|l|}{ Pea shoots } \\
\hline & Day 1 & Day 10 \\
\hline Macronutrient composition & $\%$ & \\
\hline Water & $91.5 \pm 0.2$ & $91.6 \pm 0.1$ \\
\hline Protein & $4.0 \pm 1.0$ & $3.1 \pm 0.2$ \\
\hline Fat & $0.3 \pm 0.0$ & $0.4 \pm 0.0$ \\
\hline Ash & $0.9 \pm 0.0$ & $0.7 \pm 0.1$ \\
\hline Dietary Fiber & $2.0 \pm 0.1$ & $2.2 \pm 0.1$ \\
\hline Sugar (by difference) & $1.2 \pm 0.9$ & $2.0 \pm 0.2$ \\
\hline Energy $^{1}$ (/100 g f.w) & \multicolumn{2}{|l|}{$24.1 \mathrm{Kcal}(102.2 \mathrm{~kJ})$} \\
\hline $\begin{array}{l}\text { Micronutrient composition } \\
\pm \text { sd Water-soluble vitamins }\end{array}$ & \multicolumn{2}{|l|}{ mg/100 g f.w. } \\
\hline $\begin{array}{l}\text { Ascorbic Acid (C) } \\
19.30\end{array}$ & $153.94 \pm 2.81$ & $174.05 \pm$ \\
\hline Thiamine (B1) & $0.18 \pm 0.02$ & $0.19 \pm 0.01$ \\
\hline Riboflavin (B2) & $0.13 \pm 0.04$ & $0.13 \pm 0.01$ \\
\hline Nicotinamide (B3) & $0.14 \pm 0.02 *$ & $0.10 \pm 0.00 *$ \\
\hline Pantothenic Acid (B5) & $0.64 \pm 0.03^{*}$ & $1.19 \pm 0.03^{*}$ \\
\hline Pyridoxine(B6) & $0.02 \pm 0.00 *$ & $0.05 \pm$ \\
\hline \multicolumn{3}{|l|}{$0.00 *$ Fat-solublevitamins } \\
\hline Vitamin E ( $\alpha$-tocopherol) & $2.65 \pm 0.09 *$ & $3.66 \pm$ \\
\hline $0.07^{*}$ Vitamin A (RAE eq. $)^{2}$ & $\begin{array}{l}1.42 \pm 0.01 \\
0.06\end{array}$ & $1.36 \pm$ \\
\hline \multicolumn{3}{|l|}{ Minerals } \\
\hline $\begin{array}{l}\text { Potassium } \\
\text { Sodium } \\
\text { Calcium } \\
\text { Magnesium } \\
\text { Phosphorus } \\
\text { Iron } \\
\text { Manganese } \\
\text { Zinc } \\
\text { Copper }\end{array}$ & $\begin{array}{l}315.97 \pm 8.30^{*} \\
5.08 \pm 0.24 * \\
57.59 \pm 2.69 \\
27.20 \pm 1.60 \\
96.14 \pm 1.81 \\
1.47 \pm 0.02 \\
0.35 \pm 0.02 \\
0.46 \pm 0.03 \\
0.14 \pm 0.01 *\end{array}$ & $\begin{array}{l}332.4 \pm \\
6.46 \pm \\
58.17 \pm \\
27.84 \pm \\
90.12 \pm \\
1.48 \pm 0.02 \\
0.33 \pm 0.01 \\
0.49 \pm 0.01 \\
0.12 \pm\end{array}$ \\
\hline
\end{tabular}

1 Calculated accordingly to Atwater Factors (Otten et al., 2006).

2 RAE = Retinolactivityequivalent.

\subsection{Nutritional composition}

The macro and the micronutrient contents of pea shoots are present- ed in Table 2. The macronutrient composition was similar to other baby leaf vegetables, like spinach, lamb's lettuce or watercress (Martins, 2010). However, these leaves showed a higher percentage of protein (approximately 3\%) and dietary fiber (approximately $2 \%$ ) than the ones found in lettuces ( $1.8 \%$ and $1.3 \%$ of protein and dietary fiber, respectively), commonly present in ready-to-eat salads (Martins, 2010). All macronutrients showed a stable content during storage.

Regarding the micronutrient composition, pea shoots showed to be a good source of vitamin C, Vitamin E and vitamin A. Vitamin C repre- sented more than $96 \%$ of the total vitamin content, followed by vitamin
E and vitamin A. These vitamins levels were higher than the ones found in other common green leafy vegetables, especially in the case of vitamin C(Santos et al., 2012). Regarding the water-soluble vitamins

from the B group, the highest values were found for pantothenic acid (B5). The mineral composition revealed that pea shoots are also a good source of potassium and phosphorous. On the other hand, sodium, calcium and magnesium contents were lower than the levels found in other baby-leaf vegetables (Santos et al., 2014). Concerning the microminerals (iron, manganese, zinc and copper), they represent $0.5 \%$ of the total mineral content determined. Iron was the most abun- dant, but zinc levels were higher than those reported in other common baby-leaf vegetables (Santos et al., 2014), revealing that these leaves could enhance the zinc content of a readyto-eat salad. In this sense, the micronutrient composition, especially vitamin C, vitamin $E$, vitamin $A$, potassium and zinc contents, are the most distinguishable character- istics of pea shoots in relation to other baby-leaf vegetables.

The nutritional quality of pea shoots revealed some variations throughout storage, mostly in their vitamin content. Pyridoxine re- vealed the highest variation (+57\%) between sampling days, followed

by pantothenic acid (+46\%), nicotinamide $(-35 \%)$ and vitamin $E(+28 \%)$. This behavior was also described in other leafy vegetables,

being referred in some studies the occurrence of vitamin synthesis in the post-harvest period (Sánchez-Mata, Cámara, \& Díez-Marqués, 2003; Santos et al., 2012). Moreover the enzymatic action against the conjugated form of the vitamins could originate higher levels of free form of the vitamin throughout the storage (Hounsome, Hounsome, Tomos, \& Edwards-Jones, 2009; Santos et al., 2012). The mineral content showed less variation, and could be considered stable during the studied period.

\subsection{Carotenoid profile}

The fat-soluble pigments extracted from pea shoots (carotenoids and chlorophylls) were successfully separated by the chromatographic conditions employed (see Fig. 1). From the obtained UV-vis spectra information it was possible to identify 26 compounds, corresponding 12 to carotenoids and the other to chlorophyll $a$ and $b$ and their deriva- tives. A tentative identification of the six main separated carotenoid compounds was accomplished by comparing the UV-vis and MS spectra information provided by the two detectors (i.e., DAD and MS) with commercial standards and data from the literature (Britton, Liaaen- Jensen, \& Pfander, 2004; Castro-Puyana et al., 2013; Crupi, Milella,

\& Antonacci, 2010). Information about characteristic UV-Vis spectra, [M + $\mathrm{H}^{+}$, and the main fragments obtained by $\mathrm{MS}^{2}$ experiments for the different carotenoids is presented in Table 3, together with their quantification in the two sampling days. In MS detection the caroten- oids were detected as protonated molecules $[\mathrm{M}+\mathrm{H}]^{+}$, with exception 
Fig. 1. HPLD-DAD chromatogram $(450 \mathrm{~nm})$ of the carotenoid profile of peas shoots. For peak identification and information see Table $3(c$, correspond to carotenoid compounds not completely identified).

Table 3

Carotenoids from pea shoots: retention time (Rt), UV-vis maxima, mass spectral data, tentative identification and concentration (mean value \pm standard deviation relative to fresh weight (f.w.); * means a significant variation ( $\mathrm{p}$ b 0.05) between sampling days).

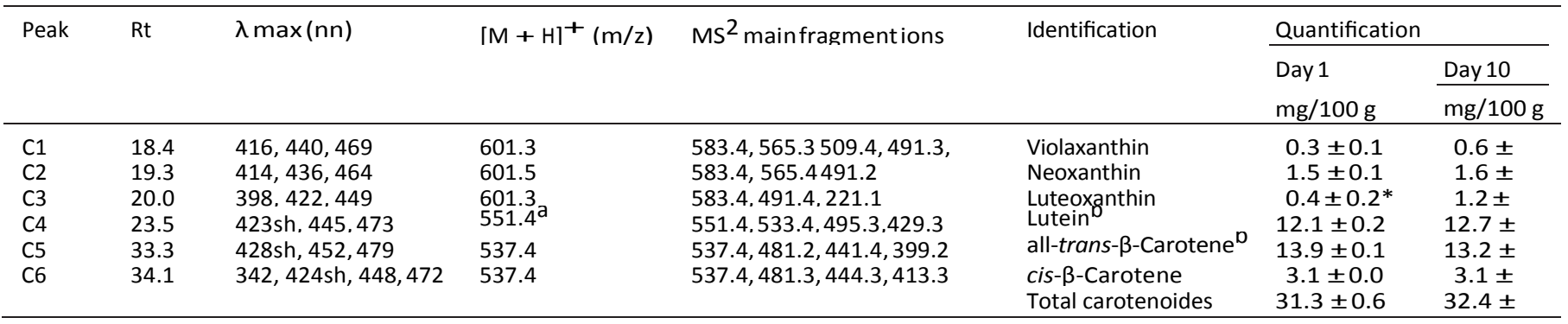

sh, spectral shoulder.

a $[\mathrm{M}+\mathrm{H}-\mathrm{H} 2 \mathrm{O}]^{+}$.

b Identification corroborated using commercial standards.

of lutein (peak C4) identified by the dehydrated fragment ion $\left[\mathrm{M}+\mathrm{H}-\mathrm{H}_{2} \mathrm{O}\right]^{+}$ (Castro-Puyana et al., 2013). This ion was also detected as a fragment ion in the other hydroxylated carotenoids (peaks $\mathrm{C} 1, \mathrm{C} 2$ and $\mathrm{C} 3$ ) at a $\mathrm{m} / \mathrm{z}$ of $583[\mathrm{M}$ $\left.+\mathrm{H}_{-} \mathrm{H}_{2} \mathrm{O}\right]^{+}$. These three compounds had the same protonated molecules at a $\mathrm{m} / \mathrm{z}$ of $601[\mathrm{M}+\mathrm{H}]^{+}$and share the same fragmentation ions. Their identification was based on the different relative intensities of the main $\mathrm{MS}^{2}$ fragment ions and on their maxima UV-vis spectra. The fragmentation profile of violaxanthin (C1) showed five different main ions (Table 3), while in the other xanthophylls (neoxanthin (C2) and luteoxanthin (C3)) only 3 of those ions were present. The compounds $\mathrm{C} 5$ and $\mathrm{C} 6$ also presented a similar MS spec- trum, however, in this case the presence in compound $\mathrm{C} 6$ of shift of absorption maxima (approximately $4 \mathrm{~nm}$ with respect to the $\mathrm{C5}$ ) and a low peak at $342 \mathrm{~nm}$ permitted the identification of $c i s-\beta$-carotene.

Pea shoots revealed a mean carotenoid content of $31.9 \pm 0.8 \mathrm{mg} / 100 \mathrm{~g}$ (f.w.), being $\beta$-carotene and lutein the main carotenoids of the pea leaves composition, representing each about $40 \%$ of the total carot- enoid content (Table 3). The other xanthophylls were present in lower amounts, being this a typical carotenoid profile of a dark green leafy vegetable (Reif, Arrigoni, Schärer, Nyström, \& Hurrell, 2013). Although there are no specific value proposed for the daily intake of carotenoids, there are epidemiological evidence suggesting that higher blood concentrations of $\beta$-carotene and other carotenoids obtained from foods are associated with a lower risk of several chronic diseases and reduc- tion of eye diseases (Otten et al., 2006). Recent studies have linked the consumption of fruit and vegetables and a higher carotenoid intake with a lower risk of invasive bladder cancer among women (Park et al., 2013) and esophageal cancer (Ge, Xing, Yu, \& Shen, 2013). In this sense, pea shoots can be considered a good source of these com- pounds, especially $\beta$-carotene, that has provitamin-A activity, and lutein that is a component of the human retina. Besides, all carotenoids would contribute to the antioxidant properties of this product.

The carotenoid degradation is common during the senescence of the leaves, being also affected by the presence of light during post-harvest storage (Kidmose et al., 2002). In pea shoots, the global carotenoid content was stable during the storage period, revealing, once more, the stability of the nutritional quality of this product.

\subsection{Flavonoid characterization}

The presence of several flavonoid glycosides was observed in the native extract of pea shoots. However, before the characterization of

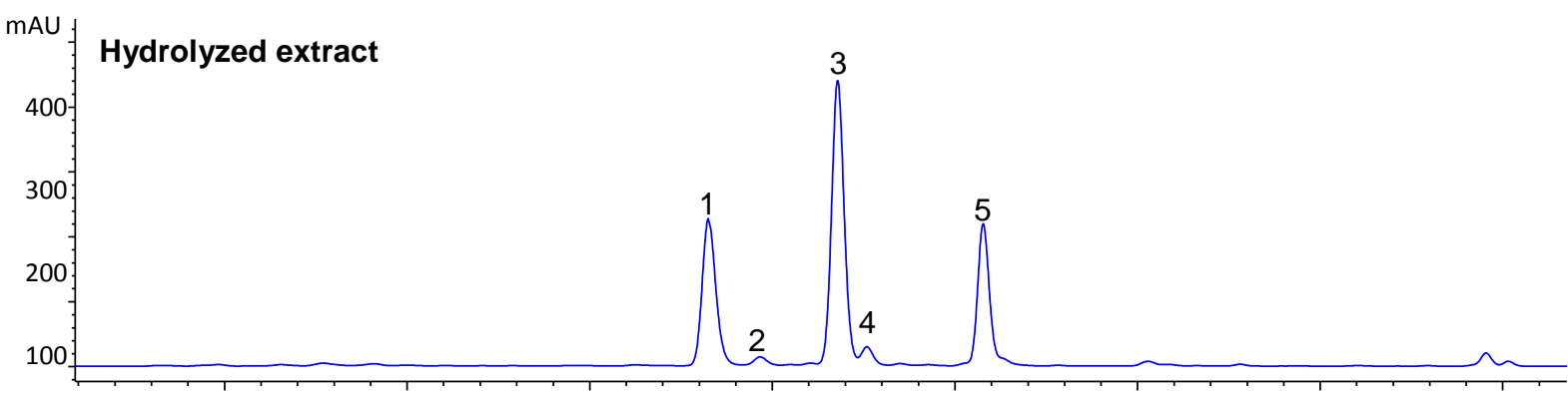

0 20 


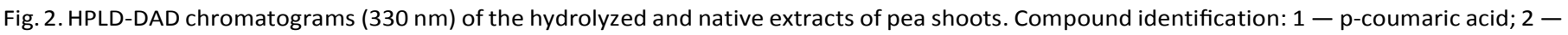
ferulic acid; 3 - quercetin-3-O- sophorotrioside; 4 - sinapic acid; 5 - kaempferol-3-O-sophorotrioside; 6 - isomer from 5; 7 - quercetin-3(caffeoyl-diglucoside)-7-glucoside; 8 - quercetin-3-(p-coumaroyl- diglucoside)-7-glucoside; 9 - quercetin-3-feruloylsophoroside-7-glucoside; 10 quercetin-3-O-(glucuronide-diglucoside)-7-glucoside; 11 - kaempferol-3-sinapoylsophotrioside; 12 - kaempferol-3-(p-coumaroyl-diglucoside)-7glucoside; 13 - kaempferol-3-feruloylsophoroside-7-glucoside; 14 - kaempferol-3-O-sophorotrioside-7-glucoside; 15 - isomer from 12. 


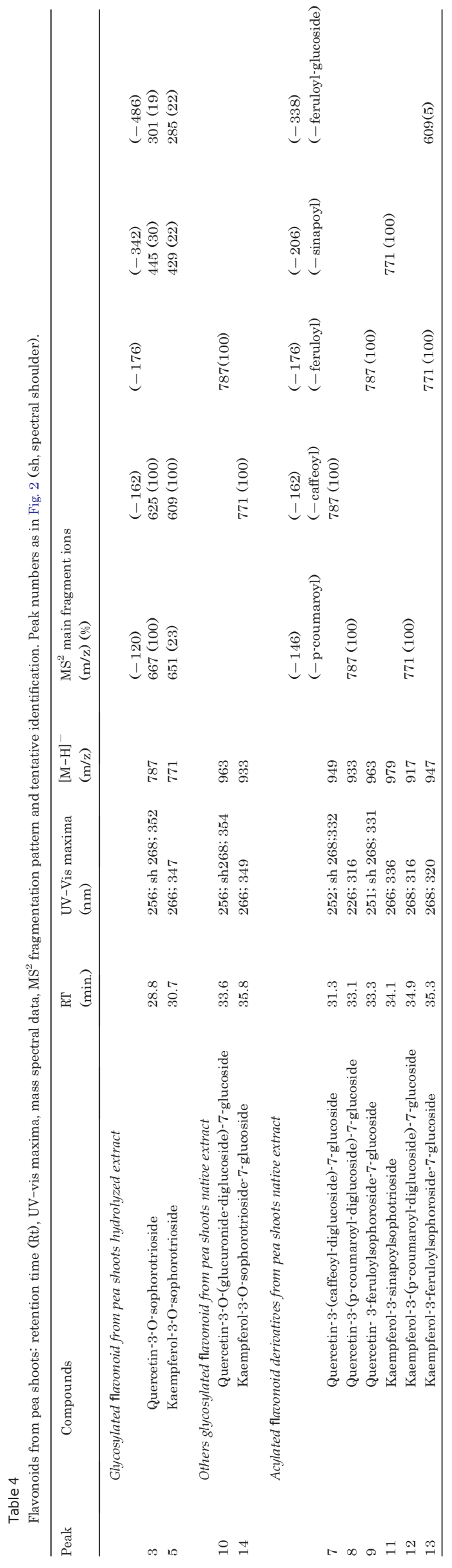

the compounds in the native extract, the deacylated compounds were studied in the hydrolysed extract. In this extract 5 major compounds were identified (see Fig. 2), according to their UV-vis spectra as flavonol-3-O-glycosides (peaks 3 and 5) and hydroxycinnamic acids (peaks 1, 2 and 4) (Table 4). The MS analysis of the flavonols revealed the presence of a molecular ion at $\mathrm{m} / \mathrm{z} 787\left([\mathrm{M}-\mathrm{H}]^{-}\right)$and $\mathrm{m} / \mathrm{z} 771\left([\mathrm{M}-\mathrm{H}]^{-}\right)$for peak 3 and 5, respectively. The ions obtained in the $\mathrm{MS}^{2}$ experiment allowed the identification of these compounds as quercetin (peak 3) and kaempferol (peak 5) glycosylated with a sophorotrioside unit (Table 4). The fragmentation pattern obtained was in agreement with the results described in the literature for the identified compounds (Ferreres, Llorach, \& Gil-Izquierdo, 2004). The other compounds found in the hydrolyzed extract correspond to $p$-coumaric acid $(\mathrm{m} / \mathrm{z} 163$,

$\left.[\mathrm{M}-\mathrm{H}]^{-}\right)$, ferulic acid $\left(\mathrm{m} / \mathrm{z} 193,[\mathrm{M}-\mathrm{H}]^{-}\right)$and sinapic acid $(\mathrm{m} / \mathrm{z} 223$,

$[\mathrm{M}-\mathrm{H}]^{-}$) (Fig. 2).

The analysis of flavonoid compounds present in the native extract permitted to detect, by their typical UV spectra, 5 flavonol 3-Oglycosides compounds (peaks 3, 5, 6, 10 and 14) and 7 peaks of acylated

flavonols (compounds 7, 8, 9, 11, 12, 13 and 15). The first group present- ed an UV-vis spectra with a maximum between 350 and $385 \mathrm{~nm}$, while the second group had a UV-vis spectral shape that resembles the over- lapping of a flavonol spectrum with a hydroxycinnamic acid, with a maximum around 310-330 nm (Carazzone, Mascherpa, Gazzani, \& Papetti, 2013). The MS analysis allowed to identify these compounds as quercetin and kaempferol derivatives. Compounds 3 and 5, previous- ly identified in the hydrolyzed extract, were also present in the native pea shoots extract but in minor amounts. The acylated flavonols were the main compounds in the flavonoid profile of pea shoots (see Fig. 2), especially the compound 8 (m/z 933 [M$\mathrm{H}^{-}$) identified as quercetin- 3-(p-coumaroyl-diglucoside)-7-glucoside and compound $12\left(\mathrm{~m} / \mathrm{z} 917[\mathrm{M}-\mathrm{H}]^{-}\right)$identified as kaempferol-3-(p-coumaroyldiglucoside)-7-glucoside. In both compounds the $\mathrm{MS}^{2}$ experiment revealed a loss of $146 \mathrm{mu}$, corresponding to the loss of a p-coumaroyl unit (Table 4). The presence of these compounds was also described in the flavonoid composition of othergreen leafy vegetables (Lin, Sun, Chen, \& Harnly, 2011).

Pea shoots had a mean flavonoid content of $329 \pm 1 \mathrm{mg} / 100 \mathrm{~g}$ (f.w.) (see Fig. 3), which indicates pea shoots as a good source of these antiox- idant compounds. Quercetin derivatives represent $67 \%$ of the total flavonoids. During the storage, no significant changes ( $p$ b 0.05) were observed, in agreement with other reports that mention a greater stabil- ity of the glycosylated flavonoids in relation to other phenolic com-pounds like the hydroxybenzoic or hydroxycinnamic acids (Martínez- Sánchez, Marín, Llorach, Ferreres, \& Gil,2006).

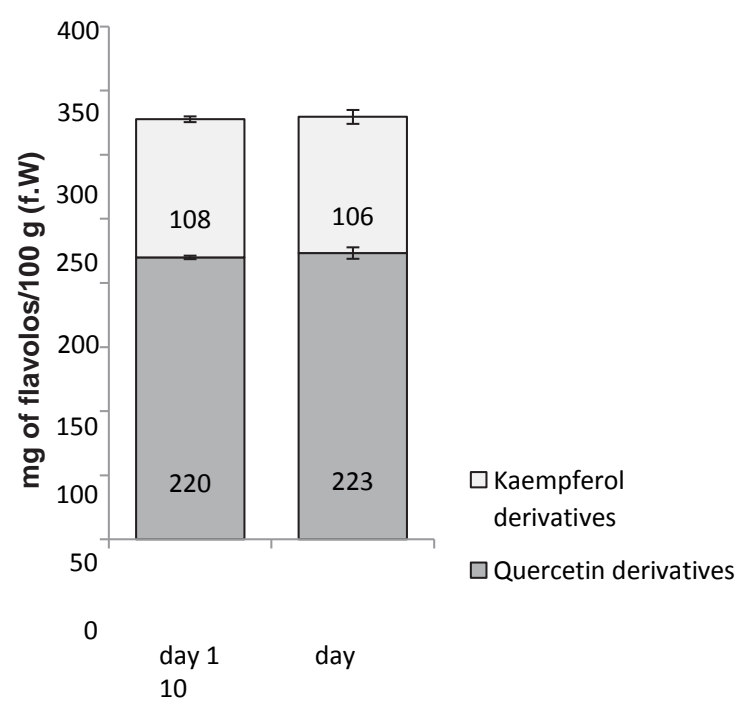

Fig. 3. Flavonoid content from pea shoots at the beginning and at end of storage period. 


\section{Conclusions}

The results achieved in the present study demonstrated that fresh pea shoots are a good source of different micronutrients, with sig- nificant amounts of biologically active compounds. The inclusion of these leaves in the diet can contribute to a higher intake of antioxidant compounds like flavonoids, carotenoids and vitamin C, and to the daily requirements of minerals, especially potassium. As a minimally proc- essed vegetable, the pea shoots showed a very good stability of their main quality characteristics, when stored under refrigerated conditions for 10 days. The results presented in this work can be also useful to complete food composition databases with the inclusion of a new option of a nutritious green leafy vegetal.

\section{Acknowledgments}

Joana Santos is thankful to FCT for the PhD grant SFRH/BD/66476/ 2009 financed by POPH-QREN and subsidized by ESF and MCTES. M.H. would like to thank MICINN for a "Ramón y Cajal" research contract. This work had been supported by Fundação para a Ciência e Tecnologia through project no. PEstC/EQB/LA0006/2013 and NORTE-07-0124- FEDER-000069-Food Science. The authors thank Iberian Salads S.A for the vegetable samples used in this study and also to Dra. Ana Paula Vale from ESA-Instituto Politécnico de Viana do Castelo for thehelp pro- vided in the dietary fiber determinations.

References

AOAC. (2000). Official Method of Analysis of AOAC International (17th ed.). Barrett, D.M., Beaulieu, J. C., \& Shewfelt, R. (2010). Color, flavor, texture, and nutritional quality of fresh-cut fruits and vegetables: desirable levels, instrumental and sensory measurement, and the effects of processing. Critical Reviews in Food Science and Nutrition, 50(5), 369-389.

Britton, G., Liaaen-Jensen, S., \& Pfander, H. (2004). Carotenoids handbook. Basel: Birkhäuser. Carazzone, C., Mascherpa, D., Gazzani, G., \& Papetti, A. (2013). Identification of phenolic constituents in red chicory salads (Cichorium intybus) by high-performance liquid chromatography with diode array detection and electrospray ionisation tandem mass spectrometry. Food Chemistry, 138(2-3), 1062-1071.

Castro-Puyana, M., Herrero, M., Urreta, I., Mendiola, J., Cifuentes, A., Ibáñez, E., \& Suárez-Alvarez, S. (2013). Optimization of clean extraction methods to isolate carot- enoids from the microalga Neochloris oleoabundans and subsequent chemical charac- terization using liquid chromatography tandem mass spectrometry. Analytical and Bioanalytical Chemistry, 405(13), 4607-4616.

Crupi, P., Milella, R. A., \& Antonacci, D. (2010). Simultaneous HPLC-DAD-MS $(\mathrm{ESI}+)$ deter- mination of structural and geometrical isomers of carotenoids in mature grapes. Journal of Mass Spectrometry, 45(9), 971-980.

Edelenbos, M., Christensen, L. P., \& Grevsen, K. (2001). HPLCDetermination of Chlorophyll and Carotenoid Pigments in Processed Green Pea Cultivars (Pisum sativum L.). Journal of Agricultural and Food Chemistry, 49(10), 4768-4774.

FAO (2013). FAO Statistic Year Book 2012. Rome, Italy.

Ferreres, F., Llorach, R., \& Gil-Izquierdo, A. (2004). Characterization of the interglycosidic linkage in di-, tri-, tetra- and pentaglycosylated flavonoids and differentiation of positional isomers by liquid chromatography/electrospray ionization tandem mass spectrometry. Journal of Mass Spectrometry, 39(3), 312-321.

Francisco, M., Moreno, D. A., Cartea, M. E., Ferreres, F., García-Viguera, C., \& Velasco, P. (2009). Simultaneous identification of glucosinolates and phenolic compounds in a representative collection of vegetable Brassica rapa. Journal of Chromatography A, 1216(38), 6611-6619.

Ge, X. -X., Xing, M. -Y., Yu, L. -F., \& Shen, P. (2013). Carotenoid Intake and Esophageal Cancer Risk: a Meta-analysis. Asian Pacific Journal of Cancer Prevention, 14 (3), 1911-1918.Greenberg, A. E., Clesceri, L. S., \& Eaton, A. D. (1992). Standard method 4500-P. In Standard Methods for the Examination Of Water and Wastewater (18th ed.). USA: American Public Health Association Publications.
Greenberg, A. E., Clesceri, L. S., Eaton, A. D., \& Shen, P. (1992). Standard method 4500-P. In Standard Methods for the Examination Of Water and Wastewater (18th ed.). USA: American Public Health Association Publications. 
Hamada, A.M., \& El-Enany, A. E. (1994). Effect of $\mathrm{NaCl}$ salinity on growth, pigment and mineral element contents, and gas exchange of broad bean and pea plants. Biologia Plantarum, 36(1), 75-81.

Hanson, P., Yang, R. -Y., Chang, L. -C., Ledesma, L., \& Ledesma, D. (2011). Carotenoids, ascorbic acid, minerals, and total glucosinolates in choysum (Brassica rapa cvg. parachinensis) and kailaan (B. oleraceae Alboglabra group) as affected by variety and wet and dry season production. Journal of Food Composition and Analysis, 24(7), 950-962.

Hinojosa, A., Silveira, A.C., Ospina, M., Char, C., Sáenz, C., \& Escalona, V. H. (2013). Safety of ready-to-eat watercress using environmentally friendly sanitization methods. Journal of Food Quality, 36(1), 66-76.

Hounsome, N., Hounsome, B., Tomos, D., \& Edwards-Jones, G. (2009) Changes in antiox- idant compounds in white cabbage during winter storage. Postharvest Biology and Technology, 52(2), 173-179.

Kidmose, U., Edelenbos, M., \& R.N. (2002). Colour stability in vegetables. In D. B. MacDougall (Ed.), Colour in Food: Improving Quality. Cambridge, UK: CRC Press.

Lin, L. -Z., Sun, J., Chen, P., \& Harnly, J. (2011). UHPLC-PDA-ESI/HRMS/MSn analysis of an-

thocyanins, flavonol glycosides, and hydroxycinnamic acid derivatives in red mustard greens (Brassica juncea coss variety). Journal of Agricultural and Food Chemistry, 59(22), 12059-12072.

Martínez-Sánchez, A., Luna, M. C., Selma, M. V., Tudela, J. A., Abad, J., \& Gil, M. I. (2012). Baby-leaf and multi-leaf of green and red lettuces are suitable raw materials for the fresh-cut industry. Postharvest Biology and Technology, 63(1), 1-10.

Martínez-Sánchez, A., Marín, A., Llorach, R., Ferreres, F., \& Gil, M. I. (2006). Controlled atmosphere preserves quality and phytonutrients in wild rocket (Diplotaxis tenuifolia). Postharvest Biology and Technology, 40(1), 26-33.

Martins, I. (2010). Tabela da Composição de Alimentos. Lisboa, Portugal: Instituto Nacional de Saúde Ricardo Jorge.

Miles, C. A., \& Sonde, M. (2003). Pea Shoots. Pacific Northwest Extension Publications, PNW, 567, 1-8.

Miron, T. L., Plaza, M., Bahrim, G., Ibáñez, E., \& Herrero, M. (2011). Chemical composition of bioactive pressurized extracts of Romanian aromatic plants. Journal of Chromatography A, 1218(30), 4918-4927.

Otten, J. J., Hellwig, J. P., \& Meyers, L. D. (2006). Dietary Reference Intakes: The EssentialGuide to Nutrient Requirements. United States of America: National Academies Press.

Park, S. Y., Ollberding, N. J., Woolcott, C. G., Wilkens, L. R., Henderson, B. E., \& Kolonel,

L. N. (2013). Fruit and vegetable intakes are associated with lower risk of bladder cancer among women in the Multiethnic Cohort Study. Journal of Nutrition, 143(8),1283-1292.

Pea shoots (2013). http://www.peashoots.com/peashootsnutrition.htm (Accessed 20/11/2013)

Poiroux-Gonord, F., Bidel, L. P. R., Fanciullino, A. -L., Gautier, H. I. N., LauriLopez, F. I, \& Urban, L. (2010). Health benefits of vitamins and secondary metabolites of fruits and vegetables and prospects to increase their concentrations by agronomic approaches. Journal of Agricultural and Food Chemistry, 58(23), 12065-12082.

Reif, C., Arrigoni, E., Schärer, H., Nyström, L., \& Hurrell, R. F. (2013). Carotenoid database of commonly eaten Swiss vegetables and their estimated contribution to carotenoid intake. Journal of Food Composition and Analysis, 29(1), 64-72.

Rico, D., Martín-Diana, A.B., Barat, J. M., \& Barry-Ryan, C. (2007). Extending and measuring the quality of fresh-cut fruit and vegetables: a review. Trends in Food Science \& Technology, 18(7), 373-386.

Roura, S. I., Davidovich, L. A., \& del Valle, C. E. (2000). Quality loss in minimally processed swiss chard related to amount of damaged area. LWT - Food Science and Technology, 33(1), 53-59.

Sánchez-Mata, M. C., Cámara, M., \& Díez-Marqués, C. (2003). Extending shelf-life and nutritive value of green beans (Phaseolus vulgaris L.), by controlled atmosphere storage: micronutrients. Food Chemistry, 80(3), 317-322.

Santos, J., Mendiola, J. A., Oliveira, M. B. P. P., Ibáñez, E., \& Herrero, M. (2012). Sequential determination of fat- and water-soluble vitamins in green leafy vegetables during storage. Journal of Chromatography A, 1261, 179-188.

Santos, J., Oliva-Teles, M. T., Delerue-Matos, C., \& Oliveira, M. B. P. P.
(2014). Multi-elemental analysis of ready-to-eat "baby leaf" vegetables using microwave digestion and high-resolution continuum source atomic absorption spectrometry. Food Chemistry, 151, 311-316.

Smýkal, P., Coyne, C. J., Redden, R., \& Maxted, N. (2013). Pea (Pisum sp.) genetic resources, its analysis and exploration. In E. Insights (Ed.), Plant Germplasm Introduction and Testing (pp. 157-180) (London, United Kingdom).

Tomás-Callejas, A., Boluda, M., Robles, P. A., Artés, F., \& ArtésHernández, F. (2011). Innovative active modified atmosphere packaging improves overall quality of fresh-cut red chard baby leaves. LWT - Food Science and Technology, 44(6), 1422-1428.

Wong, C., Bhalla, P., Ottenhof, H., \& Singh, M. (2008). Transcriptional profiling of the pea shoot apical meristem reveals processes underlying its function and maintenance. BMC Plant Biology, 8(1), 73. 